\title{
A NEW METHOD FOR SOLVING OF TELEGRAPH EQUATION WITH HAAR WAVELET
}

\section{Majid. Erfanian, Morteza. Gachpazan}

\begin{abstract}
:
In this paper we have introduced a computational method for a class of Telegraph Equation change to two-dimensional nonlinear Volterra integral equations, based on the expansion of the solution as a series of Haar functions. Also, by using the Banach fixed point theorem, we get an upper bound for the error of our method. Since our examples in this article are selected from different references, so the numerical results obtained here can be compared with other numerical methods.

keywords
\end{abstract}

Telegraph Equation, two-dimensional nonlinear Volterra integral equations; Rationalized Haar wavelet; Operational matrix; fixed point theorem; error analysis.

MSC 2010: 47A56; 45B05; 47H10; $42 \mathrm{C} 40$.

\section{Introduction}

The first working telegrapher's equation was built by Atlantic Telegraph Company In December 1856. That Thompson's mathematical model for the signal conduction through cables was based on Fourier's equations for heat conduction in a wire. But early 1850 s the question of a transatlantic telegraph line was raised, and the question appealed so much to the physicist William Thomson, later Lord Kelvin, that he started developing a mathematical theory for signal decay in underwater telegraph cables. In telegrapher's equation describing the variation of voltage $u$ along an electrical cable as function of time and position,

$\mathrm{u}_{t t}+(\alpha+\beta) \mathrm{u}_{\mathrm{t}}+\alpha \beta \mathrm{u}=\mathrm{c}^{2} \mathrm{u}_{\mathrm{xx}}$.

Where $\mathrm{c}^{2}=\frac{1}{L C}, \alpha=\frac{G}{C}, \beta=\frac{R}{L}$ which consists of a

resistor of resistance $R$, a coil of inductance, $L$, a

resistor of conductance $G$, or a capacitor of

capacitance $C$. In 1893 , the physicist Oliver

Department of Science, School of Mathematical Sciences, University of Zabol, Zabol, Iran Department of Applied Mathematics, School of Mathematical Sciences, Ferdowsi University of Mashhad, Mashhad, Iran
Heavyside showed that if $\frac{R}{L}$ could be made equal to $\frac{G}{C}$ (or $R C=G L$ ), a constant velocity of propagation would result and the attenuation would be minimized. The equation is a special case of nonlinear Cauchy problem as follow:

$\frac{\partial^{2} \mathrm{u}}{\partial \mathrm{t}^{2}}+\frac{\partial}{\partial \mathrm{t}}(\mathrm{f}(\mathrm{x}, \mathrm{t}, \mathrm{u}))=\frac{\partial^{2} \mathrm{u}}{\partial \mathrm{x}^{2}}+\frac{\partial}{\partial \mathrm{x}}(\mathrm{g}(\mathrm{x}, \mathrm{t}, \mathrm{u}))+\mathrm{h}(\mathrm{x}, \mathrm{t}, \mathrm{u})$. Which

$(x, \mathrm{t}) \in \mathrm{W}:=\{(\mathrm{x}, \mathrm{t}): \mathrm{x}+\mathrm{t} \geq 0, \quad \mathrm{x}-\mathrm{t} \geq 0\}$, With the change of variables $x^{\prime}=x+t$ and $t^{\prime}=x-t$, we have

or

$$
\frac{\partial^{2} \mathrm{U}}{\partial x^{\prime} \partial t^{\prime}}+\frac{\partial}{\partial t^{\prime}}(g-f)+\frac{\partial}{\partial x^{\prime}}(g+f)=-h,
$$

That

$$
\frac{\partial^{2} \mathrm{U}}{\partial x^{\prime} \partial t^{\prime}}-\frac{\partial F}{\partial \mathrm{t}^{\prime}}-\frac{\partial \mathrm{G}}{\partial \mathrm{x}^{\prime}}=\mathrm{H} \text {. }
$$

$$
\begin{gathered}
\mathrm{U}\left(\mathrm{x}^{\prime}, \mathrm{t}^{\prime}\right)=\frac{1}{4} \mathrm{u}\left(\frac{\mathrm{x}^{\prime}+\mathrm{t} \mathrm{t}^{\prime}}{2}, \frac{\mathrm{x} \mathrm{x}^{\prime}-\mathrm{t}^{\prime}}{2}\right), \\
\mathrm{H}\left(\mathrm{x}^{\prime}, \mathrm{t}^{\prime}, \mathrm{U}\right)=-\frac{1}{4} \mathrm{~h}\left(\mathrm{x}^{\prime}, \mathrm{t}^{\prime}, \mathrm{U}\right), \\
\mathrm{F}\left(\mathrm{x}^{\prime}, \mathrm{t}^{\prime}, \mathrm{U}\right)=\frac{1}{4}\left(\mathrm{f}\left(\mathrm{x}^{\prime}, \mathrm{t}^{\prime}, \mathrm{U}\right)-\mathrm{g}\left(\mathrm{x}^{\prime}, \mathrm{t}^{\prime}, \mathrm{U}\right)\right) \\
\mathrm{G}\left(\mathrm{x}^{\prime}, \mathrm{t}^{\prime}, \mathrm{U}\right)=-\frac{1}{4}\left(\mathrm{f}\left(\mathrm{x}^{\prime}, \mathrm{t}^{\prime}, \mathrm{U}\right)+\mathrm{g}\left(\mathrm{x}^{\prime}, \mathrm{t}^{\prime}, \mathrm{U}\right)\right) .
\end{gathered}
$$

With the integration of the $x^{\prime}, t^{\prime}$ we have:

$$
\begin{aligned}
& \int_{0}^{\mathrm{T}} \int_{0}^{\mathrm{x}} \frac{\partial^{2} \mathrm{U}\left(\mathrm{x}^{\prime}, \mathrm{t}^{\prime}\right)}{\partial \mathrm{x}^{\prime} \partial \mathrm{t}^{\prime}} \mathrm{dx}^{\prime} \mathrm{dt}^{\prime} \\
& =\int_{0}^{\mathrm{T}} \int_{0}^{\mathrm{x}} \frac{\partial \mathrm{F}\left(\mathrm{x}^{\prime}, \mathrm{t}^{\prime}, \mathrm{U}\left(\mathrm{x}^{\prime}, \mathrm{t}^{\prime}\right)\right)}{\partial \mathrm{x}^{\prime}} \mathrm{dx}^{\prime} \mathrm{dt}^{\prime} \\
& +\int_{0}^{\mathrm{T}} \int_{0}^{\mathrm{x}} \frac{\partial \mathrm{G}\left(\mathrm{x}^{\prime}, \mathrm{t}^{\prime}, \mathrm{U}\left(\mathrm{x}^{\prime}, \mathrm{t}^{\prime}\right)\right)}{\partial \mathrm{t}^{\prime}} \mathrm{dx}^{\prime} \mathrm{dt}^{\prime} \\
& +\int_{0}^{\mathrm{T}} \int_{0}^{\mathrm{x}} \mathrm{H}\left(\mathrm{x}^{\prime}, \mathrm{t}^{\prime}, \mathrm{U}\left(\mathrm{x}^{\prime}, \mathrm{t}^{\prime}\right)\right) \mathrm{dx}^{\prime} \mathrm{dt}^{\prime} .
\end{aligned}
$$

Thus

$$
\begin{aligned}
& \mathrm{U}(\mathrm{X}, \mathrm{T})=\int_{0}^{\mathrm{T}} \int_{0}^{\mathrm{X}} \mathrm{H}\left(\mathrm{x}^{\prime}, \mathrm{t}^{\prime}, \mathrm{U}\left(\mathrm{x}^{\prime}, \mathrm{t}^{\prime}\right)\right) \mathrm{dx}^{\prime} \mathrm{dt}^{\prime} \\
& +\int_{0}^{\mathrm{T}}\left(\mathrm{F}\left(\mathrm{x}^{\prime}, \mathrm{t}^{\prime}, \mathrm{U}\left(\mathrm{x}^{\prime}, \mathrm{t}^{\prime}\right)\right)-\mathrm{F}\left(0, \mathrm{t}^{\prime}, \mathrm{U}\left(0, \mathrm{t}^{\prime}\right)\right)\right) \mathrm{d \textrm {t } ^ { \prime }} \\
& +\int_{0}^{\mathrm{X}}\left(\mathrm{G}\left(\mathrm{x}^{\prime}, \mathrm{t}^{\prime}, \mathrm{U}\left(\mathrm{x}^{\prime}, \mathrm{t}^{\prime}\right)\right)-\mathrm{G}\left(\mathrm{x}^{\prime}, 0, \mathrm{U}\left(\mathrm{x}^{\prime}, 0\right)\right)\right) \mathrm{dx^{ \prime }} \\
& +\mathrm{U}(\mathrm{X}, 0)+\mathrm{U}(0, \mathrm{~T})-\mathrm{U}(0,0),
\end{aligned}
$$




\section{If}

$$
\begin{array}{rl}
R(X, T)=-\int_{0}^{T} & F\left(0, t^{\prime}, U\left(0, t^{\prime}\right)\right) d t^{\prime} \\
& -\int_{0}^{X} G\left(x^{\prime}, 0, U\left(x^{\prime}, 0\right)\right) d x^{\prime} \\
& +U(X, 0)+U(0, T)-U(0,0),(3)
\end{array}
$$

Then from (2) and (3) the equation (1) is equivalent to the following $2 \mathrm{D}$ Volterra integral equation as

$$
\begin{array}{r}
\mathrm{U}(\mathrm{X}, \mathrm{T})=\int_{0}^{\mathrm{T}} \int_{0}^{\mathrm{X}} \mathrm{H}\left(\mathrm{x}^{\prime}, \mathrm{t}^{\prime}, \mathrm{U}\left(\mathrm{x}^{\prime}, \mathrm{t}^{\prime}\right)\right) \mathrm{dx}^{\prime} \mathrm{dt}^{\prime} \\
+\int_{0}^{\mathrm{T}} \mathrm{F}\left(\mathrm{x}^{\prime}, \mathrm{t}^{\prime}, \mathrm{U}\left(\mathrm{x}^{\prime}, \mathrm{t}^{\prime}\right)\right) \mathrm{d \textrm {t } ^ { \prime }} \\
+\int_{0}^{\mathrm{X}} \mathrm{G}\left(\mathrm{x}^{\prime}, \mathrm{t}^{\prime}, \mathrm{U}\left(\mathrm{x}^{\prime}, \mathrm{t}^{\prime}\right)\right) \mathrm{dx^{ \prime }}+\mathrm{R}(\mathrm{X}, \mathrm{T}) .
\end{array}
$$

The first work for the solution of two-dimensional linear Volterra integral equations has been done by Brunner and Kauthen [2], who introduced collocation and iterated collocation methods (VIE). Kauthen has extended this study to the case of linear VolterraFredholm integral equations (VFIE) [8] and Brunner has considered in [11], the case of nonlinear VIE. In general form, 2D Volterra integral equation can be rewritten as

$$
\begin{array}{r}
u(x, y)=f(x, y)+\int_{0}^{y} \int_{0}^{x} W_{1}(t, s, u(t, s)) d t d s+ \\
\alpha \int_{0}^{y} W_{2}(x, s, u(x, s)) d s \\
+\beta \int_{0}^{x} W_{3}(y, t, u(t, y)) d t .(5)
\end{array}
$$

Where $\mathrm{x}, \mathrm{y}, \mathrm{t}, \mathrm{s} \in[0,1], \mathrm{u} \in \mathrm{X}=\mathrm{C}\left([0,1]^{2}\right)$ and $\alpha, \beta \in \mathrm{R}$ and $\mathrm{f:}[0,1]^{2} \rightarrow \mathrm{R}^{2}$,

$$
W_{1}, W_{2}, W_{3}:[0,1]^{2} \times R^{2} \rightarrow R^{2},
$$

are assumed to be known continuous functions satisfying the Lipschitz condition, that is, there exist $M_{1}, M_{2}, M_{3} \geq 0$ such that:

$$
\begin{gathered}
\left|W_{1}\left(t, s, v_{1}(x, y)\right)-W_{1}\left(t, s, v_{2}(x, y)\right)\right| \\
\leq M_{1}\left|v_{1}-v_{2}\right| \\
\left|\mathrm{W}_{2}\left(\mathrm{x}, \mathrm{s}, \mathrm{v}_{1}(\mathrm{x}, \mathrm{s})\right)-\mathrm{W}_{2}\left(\mathrm{x}, \mathrm{s}, \mathrm{v}_{2}(\mathrm{x}, \mathrm{y})\right)\right| \\
\leq \mathrm{M}_{2}\left|\mathrm{v}_{1}-\mathrm{v}_{2}\right|, \\
\left|\mathrm{W}_{3}\left(\mathrm{y}, \mathrm{t}, \mathrm{v}_{1}(\mathrm{t}, \mathrm{y})\right)-\mathrm{W}_{3}\left(\mathrm{y}, \mathrm{t}, \mathrm{v}_{2}(\mathrm{t}, \mathrm{y})\right)\right| \\
\leq \\
\mathrm{M}_{3}\left|\mathrm{v}_{1}-\mathrm{v}_{2}\right|,
\end{gathered}
$$

where $v_{1}, v_{2} \in R^{2}$, and the unknown function to be determined is $\mathrm{u}:[0,1]^{2} \rightarrow \mathrm{R}^{2}$. The numerical results presented in that paper show a fast convergence of another method, when applied to integral equations. To achieve this aim it is necessary to define the integral operator, $T:\left(X,\|.\|_{\infty}\right) \rightarrow\left(X,\|.\|_{\infty}\right)$.

By applying this operator in Eq (1), we have

$$
\begin{aligned}
& T u(x, y)=f(x, y)+\int_{0}^{y} \int_{0}^{x} W_{1}(t, s, u(t, s)) d t d s \\
& +\alpha \int_{0}^{y} W_{2}(x, s, u(x, s)) d s+\beta \int_{0}^{x} W_{3}(y, t, u(t, y)) d t
\end{aligned}
$$

The Banach fixed point theorem guarantees that under certain assumptions [1], the operation of equation (1) has an unique fixed point; that is, the two-dimensional Volterra integral equation has exactly one solution.

\section{RH functions}

The orthogonal set of Haar functions is a group of square waves with magnitude of $+2^{\frac{i}{2}},-2^{\frac{i}{2}}$ and 0 , for any $i=0,1, \ldots[9]$. Lynch and Reis [5] have rationalized the Haar transform by deleting the irrational numbers and introducing the integral powers of two. This modification results in what is called the rationalized Haar transform. The RH transform preserves all the properties of the original Haar transform and can be efficiently implemented using digital pipeline architecture [14]. The corresponding functions are known as RH functions. The RH functions are composition of only three amplitude $+1,-1$ and 0 .

\section{Definition 2.1}

The RH wavelet is the function defined on the real line $R$ as follows:

$$
H(t)=\left\{\begin{array}{cc}
1 & 0<t \leq \frac{1}{2} \\
-1 & \frac{1}{2}<t<1 \\
0 & \text { otherwise. }
\end{array}\right.
$$

The RH functions $h_{l}(t)$, for any $n=1,2, \ldots$ where $l=2^{i}+j$, with $i=0,1, \ldots$ and $j=0,1, \ldots, 2^{i}-$ 1 , are defined by $h_{l}(t)=\left.H\left(2^{i} t-j\right)\right|_{[0,1]}$. That is:

$H\left(2^{\mathrm{i}} \mathrm{t}-\mathrm{j}\right)=\left\{\begin{array}{cc}1 \quad \mathrm{j} .2^{-\mathrm{i}}<t \leq\left(\mathrm{j}+\frac{1}{2}\right) 2^{-\mathrm{i}}, \\ -1\left(\mathrm{j}+\frac{1}{2}\right) 2^{-\mathrm{i}}<t<(\mathrm{j}+1) 2^{-\mathrm{i}}, \\ 0 \quad \text { otherwise. }\end{array}\right.$

Also, we define $h_{0}(t)=1$, for all $t \in[0,1)$, and integer $2^{i}, i=0,1, \ldots$, indicates the level of the wavelet and $j=0,1, \ldots, 2^{i}-1$ is the translation parameter.

Note that the basic multiplication properties of $\mathrm{RH}$ functions are as follows:

$$
h_{0}(t) h_{q}(t)=h_{q}(t) \quad \text { for } q \in Z^{+} \cup(0) \text {, }
$$

Also, it can be shown that the sequence $\left\{h_{n}\right\}_{n=0}^{\infty}$ is a complete orthogonal system in $L^{2}[0,1]$.

Note that the orthogonality property is :

$$
\begin{aligned}
\left\langle\mathrm{h}_{\mathrm{l}}(\mathrm{t}), \mathrm{h}_{\mathrm{q}}(\mathrm{t})\right\rangle=\int_{0}^{1} \mathrm{~h}_{\mathrm{l}}(\mathrm{t}) \mathrm{h}_{\mathrm{q}}(\mathrm{t}) \mathrm{dt} & \\
& =\left\{\begin{array}{lr}
2^{-\mathrm{i}} & \mathrm{l}=\mathrm{q}=2^{\mathrm{i}}+\mathrm{j}, \\
1 & \mathrm{l}=\mathrm{q}=0, \\
0 & \mathrm{l} \neq \mathrm{q} .
\end{array}\right.
\end{aligned}
$$

Where $i \in Z^{+} \cup(0)$, and $j=0,1, \ldots, 2^{i}-1$. And for $f \in C[0,1]$, the series $\sum_{n} 2^{j}\left\langle f, h_{l}\right\rangle h_{l}$, converges uniformly to $f$, (see e.g.. [16]), where 


$$
\left\langle f, h_{l}\right\rangle=\int_{0}^{\mathrm{x}} f(\mathrm{t}) h_{l}(t) d t
$$

Thus the function $f(x)$ in $L^{2}([0,1])$ can be expanded with finite terms of $\mathrm{RH}$ functions as

$$
f(x)=\sum_{l=0}^{m-1} f_{l} h_{l}(x)=\boldsymbol{f}^{T} \boldsymbol{H}(x),
$$

where $m=2^{\alpha+1}$ that $\alpha=0,1, \ldots$, and the RH function coefficients $f_{l}$ are given by:

$f_{l}=\frac{\left\langle f(x), h_{l}(x)\right\rangle}{\left\langle h_{l}(x), h_{l}(x)\right\rangle}$.

That vectors $\boldsymbol{f}$ and $\boldsymbol{H}$ are defined by

$$
\boldsymbol{f}=\left[f_{0}, f_{1}, \ldots, f_{m-1}\right]^{T},
$$

and

$\boldsymbol{H}(x)=\left[h_{0}(x), h_{1}(x), \ldots, h_{m-1}(x)\right]^{T}$,

and the integral $h_{l}(t)$ is given by

$\int_{0}^{1} h_{l}(t) d t=\left\{\begin{array}{cc}1 & 1=0, \\ 0 & l \neq 0 .\end{array}\right.$

Also we have:

$\int_{0}^{\mathrm{x}} \boldsymbol{H}(t) d t=\boldsymbol{P} \boldsymbol{H}(x)$

where $\boldsymbol{P}$ is a $m \times m$ operational matrix for integration and is defined by

$\boldsymbol{P}_{m \times m}=\frac{1}{2 m}\left(\begin{array}{cc}2 m \boldsymbol{P}_{\frac{m}{2} \times \frac{m}{2}} & -\widehat{\boldsymbol{\Phi}}_{\frac{m}{2}} \times \frac{m}{2} \\ \widehat{\boldsymbol{\Phi}}^{-1} \frac{m}{2} \times \frac{m}{2} & 0\end{array}\right)$,

wherein $\boldsymbol{\Phi}_{1 \times 1}=[1], \mathbf{P}_{1 \times 1}=\left[\frac{1}{2}\right]$, and $\widehat{\boldsymbol{\Phi}}_{m \times m}$ is given by (7), while

$\widehat{\boldsymbol{\Phi}}^{-1}{ }_{m \times m}=$

$\frac{1}{m} \widehat{\boldsymbol{\Phi}}^{T}{ }_{m \times m}$.diag $(1,1,2,2, \underbrace{2^{2}, \ldots, 2^{2}}_{2^{2}}, \underbrace{2^{3}, \ldots, 2^{3}}_{2^{3}}, \ldots, \underbrace{\frac{m}{2}, \ldots, \frac{m}{2}}_{\frac{m}{2}})$.

\section{Numerical}

\section{approximation of the solution}

In this paper we have used the successive approximations method for (5), with initial condition $u_{0}=u\left(x_{0}, y_{0}\right) \quad$ that $u_{0} \in C\left([0,1]^{2}\right)$, (usually $f(x, y))$. This iterative process will continue until a suitable error. For any $x, t \in[0,1]$, and $n \geq 1$ and $m=2^{n+1} \in \mathbb{N}$, we define recursively

$$
\begin{gathered}
+\alpha \int_{0}^{y} Q_{m}\left(\psi_{i-1}^{2}(x, s)\right) d s \\
\psi_{n-1}^{1}(t, s)=\mathrm{W}_{1}\left(\mathrm{t}, \mathrm{s}, \mathrm{u}_{\mathrm{n}-1}(\mathrm{t}, \mathrm{s})\right), \\
\psi_{n-1}^{2}(x, s)=\mathrm{W}_{2}\left(\mathrm{x}, \mathrm{s}, \mathrm{u}_{n-1}(\mathrm{x}, \mathrm{s})\right), \\
\psi_{n-1}^{3}(y, t)=\mathrm{W}_{3}\left(\mathrm{y}, \mathrm{t}, \mathrm{u}_{n-1}(\mathrm{t}, \mathrm{y})\right),
\end{gathered}
$$

we can expand $\psi_{n-1}^{i}$ for $i=1,2,3$ in terms of $\mathrm{RH}$ functions as

$$
\psi_{n-1}^{1}(t, s)=\boldsymbol{H}^{T}(t) K_{1} \boldsymbol{H}(s),
$$

$$
\begin{aligned}
& \psi_{n-1}^{2}(x, s)=\boldsymbol{H}^{T}(x) K_{2} \boldsymbol{H}(s), \\
& \psi_{n-1}^{3}(y, t)=\boldsymbol{H}^{T}(y) K_{3} \boldsymbol{H}(t),
\end{aligned}
$$

If $Q_{m}$ be an orthogonal projection with following interpolation property we have

$$
\begin{aligned}
& Q_{m}\left(\psi_{n-1}^{1}\right)(t, s)=\sum_{l=0}^{m-1} \sum_{q=0}^{m-1} k_{l q}^{(1)} h_{l}(t) h_{q}(s),(1) \\
& Q_{m}\left(\psi_{n-1}^{2}\right)(x, s)=\sum_{l=0}^{m-1} \sum_{\substack{q-1 \\
q=0}}^{m-1} k_{l q}^{(2)} h_{l}(x) h_{q}(s),(12) \\
& Q_{m}\left(\psi_{n-1}^{3}\right)(y, t)=\sum_{l=0}^{m-1} \sum_{q=0}^{m-1} k_{l q}^{(3)} h_{l}(y) h_{q}(t),(13)
\end{aligned}
$$

Note that wherein $K_{t}=\left[k_{l q}^{(t)}\right]_{m \times m}$, for $t=1,2,3$

$$
\begin{aligned}
k_{l q}^{(1)} & =2^{\frac{i+j}{2}}\left\langle h_{l}(t),\left\langle\psi^{1}(t, s), h_{q}(s)\right\rangle\right\rangle, \\
k_{l q}^{(2)} & =2^{\frac{i+j}{2}}\left\langle h_{l}(x),\left\langle\psi^{2}(x, s), h_{q}(s)\right\rangle\right\rangle \\
k_{l q}^{(3)} & =2^{\frac{i+j}{2}}\left\langle h_{l}(y),\left\langle\psi^{3}(y, t), h_{q}(t)\right\rangle\right\rangle
\end{aligned}
$$

with $i, j=0,1, \ldots$, where

$$
\begin{array}{cc}
l=2^{j}+k & k=0,1, \ldots, 2^{j}-1, \\
q=2^{i}+k^{\prime} & k^{\prime}=0,1, \ldots, 2^{i}-1,
\end{array}
$$

Now, by using the RH function vector $\boldsymbol{H}(t)$, the matrix $\widehat{\boldsymbol{\Phi}}_{m \times m}$ is defined as:

$\widehat{\boldsymbol{\Phi}}_{m \times m}=\left[\boldsymbol{H}\left(\frac{1}{2 m}\right), \boldsymbol{H}\left(\frac{3}{2 m}\right), \ldots, \boldsymbol{H}\left(\frac{2 m-1}{2 m}\right)\right]$.

For example, the eight RH functions can be written in the matrix form as

$$
\widehat{\boldsymbol{\Phi}}_{m \times m}=\left(\begin{array}{cccrrrrr}
1 & 1 & 1 & 1 & 1 & 1 & 1 & 1 \\
1 & 1 & 1 & 1 & -1 & -1 & -1 & -1 \\
1 & 1 & -1 & -1 & 0 & 0 & 0 & 0 \\
0 & 0 & 0 & 0 & 1 & 1 & -1 & -1 \\
1 & -1 & 0 & 0 & 0 & 0 & 0 & 0 \\
0 & 0 & 1 & -1 & 0 & 0 & 0 & 0 \\
0 & 0 & 0 & 0 & 1 & -1 & 0 & 0 \\
0 & 0 & 0 & 0 & 0 & 0 & 1 & -1
\end{array}\right) .
$$

Thus by using this equation we have

$$
K_{t}=\left(\widehat{\boldsymbol{\Phi}}_{m \times m}^{-1}\right)^{\boldsymbol{T}} \cdot \widehat{K}_{t} \cdot(\widehat{\boldsymbol{\Phi}})_{m \times m^{\prime}}^{-1} \quad t=1,2,3,(18)
$$

where $\widehat{K}_{t}=\left[\left(\hat{k}_{t}\right)_{i j}\right]_{m \times m}$, for $t=1,2,3$, and

$$
\begin{aligned}
& i, j=1,2, \ldots, m \text { as } \\
& \left(\hat{k}_{t}\right)_{i j}=\psi^{t}\left(\frac{2 i-1}{2 m}, \frac{2 j-1}{2 m}\right) \quad i, j=1,2, \ldots, m,
\end{aligned}
$$

and $t=1,2,3$. Thus for the 2D Volterra integral equation as we have:

$$
\begin{gathered}
u_{i}(x, y)=f(x, y)+\int_{0}^{y} \int_{0}^{x} Q_{m}\left(\psi_{i-1}^{1}(t, s) d t d s\right. \\
+\beta \int_{0}^{x} Q_{m}\left(\psi_{i-1}^{3}(t, y)\right) d t i=1,2,3, \ldots, \text { (20) }
\end{gathered}
$$

\section{Error analysis}

In this section, by using the Banach fixed point theorem, we get an upper bound for the error of the our method, and the order of convergence is analyzed.

\section{Lemma 4-1}


Let $W_{1}, W_{2}, W_{3}:[0,1]^{2} \times \mathbb{R}^{2} \rightarrow \mathbb{R}^{2}$, be continiouse and Lipschitzian with Lipschitz constants $L_{1}, L_{2}$ and $L_{3}$ such that $\left|\mathrm{W}_{\mathrm{i}}(\mathrm{x}, \mathrm{t})\right| \leq \mathrm{L}_{\mathrm{i}}$ for $i=1,2,3$, then $T$ has an unique fixed point and for all $u_{0} \in C\left([0,1]^{2}\right)$

$\left\|u-T^{i}\left(u_{0}\right)\right\|_{\infty} \leq\left\|T\left(u_{0}\right)-u_{0}\right\|_{\infty} \times \sum_{j=i}^{\infty} q^{j},(21)$

where $q=L_{1}+|\alpha| L_{2}+\beta L_{3}<1$ and $u$ is the fixed point of $T$.

\section{Proof:}

For the Fredholm Hammerstein integral equations if $y, z \in C([0,1])$, we have:

$|T(u(x, y))-T(v(x, y))|=$

| $\int_{0}^{y} \int_{0}^{x} W_{1}(t, s, u(t, s))-W_{1}(t, s, v(t, s)) d t d s+$

$\alpha \int_{0}^{y} W_{2}(x, s, u(x, s))-W_{2}(x, s, v(x, s)) d s \mid$

$+\beta \int_{0}^{x} W_{3}(y, t, u(t, y))-W_{3}(y, t, v(t, y)) d t$

$\leq \int_{0}^{y} \int_{0}^{x}\left|W_{1}(t, s, u(t, s))-W_{1}(t, s, v(t, s)) d t d s\right|$

$+|\alpha| \int_{0}^{y}\left|W_{2}(x, s, u(x, s))-W_{2}(x, s, v(x, s))\right| d s$

$+\beta \int_{0}^{x}\left|W_{3}(y, t, u(t, y))-W_{3}(y, t, v(t, y))\right| d t$

$$
\leq L_{1} \int_{0}^{y} \int_{0}^{x}|u(t, s)-v(t, s)| d t d s
$$

$+|\alpha| \int_{0}^{y}|u(x, s)-v(x, s)| d s$

$$
+\beta \int_{0}^{x}|u(t, y)-v(t, y)| d t
$$$$
\leq L_{1}|| u-v||_{\infty}+|\alpha| L_{2}|| u-v||_{\infty}
$$

$+\beta L_{3}|| u-v||_{\infty} \leq\left(L_{1}+|\alpha| L_{2}+\beta L_{3}\right)|| u-\left.v\right|_{\infty}$

By induction, for the 2D Volterra integral equation and every $n \in \mathbb{N}$ we have

$$
\left\|T^{n}(y)-T^{n}(z)\right\|_{\infty} \leq q^{n}\|y-z\|_{\infty},
$$

since $q<1$ thus we have:

$$
\sum_{n=1}^{\infty}\left\|T^{n}(y)-T^{n}(z)\right\|_{\infty}<\infty .
$$

Thus $T$ has a unique fixed point which means that (5) has a unique solution and (21) follows from the Banach fixed-point theorem.

\section{Theorem 4.1.}

Assume that $\psi_{i}^{j} \in C\left([0,1]^{2}\right), j=1,2,3$, and $\left\{u_{i}\right\}_{i \geq 1}$ is a subset of $C\left([0,1]^{2}\right)$, and the functions $W_{1}, W_{2}, W_{3} \in C\left([0,1]^{2} \times \mathbb{R}^{2}\right)$, are lipschitzian functions at its third variable, then we have $\left\|u-u_{i}\right\|_{\infty} \leq\left\|T\left(u_{0}\right)-u_{0}\right\|_{\infty} \sum_{j=i}^{\infty} q^{j}+$ $\sum_{j=1}^{i} q^{i-j} \varepsilon_{j}(22) \quad$ ).

\section{Proof}

If $L_{i-1}=\max \left\{\left\|\frac{\partial \psi_{i-1}^{j}}{\partial t}\right\|_{\infty},\left\|\frac{\partial \psi_{i-1}^{j}}{\partial s}\right\|_{\infty}\right\}, j=1,2,3$, for the 2D Volterra integral equation and $m=2^{i+1}$ such that $i=0,1, \ldots$, then

$$
\begin{gathered}
\left\|T\left(u_{i-1}\right)-u_{i}\right\|_{\infty} \leq \| \int_{0}^{y} \int_{0}^{x}\left(\psi_{i-1}^{1}(t, s)\right. \\
-Q_{m}\left(\psi_{i-1}^{1}(t, s)\right) d t d s||_{\infty}||_{\infty} \\
+|\alpha||| \int_{0}^{y}\left(\psi_{i-1}^{2}(x, s)-Q_{m}\left(\psi_{i-1}^{2}(x, s)\right) d s||_{\infty}\right. \\
+|\beta||| \int_{0}^{x}\left(\psi_{i-1}^{3}(t, y)-Q_{m}\left(\psi_{i-1}^{3}(t, y)\right) d t||_{\infty}\right. \\
\leq|| \psi_{i-1}^{1}-Q_{m}\left(\psi_{i-1}^{1}\right)||_{\infty}+|\alpha||| \psi_{i-1}^{2}-Q_{m}\left(\psi_{i-1}^{2}\right)||_{\infty} \\
+|\beta||| \psi_{i-1}^{3}-Q_{m}\left(\psi_{i-1}^{3}\right)||_{\infty} .
\end{gathered}
$$

If we define

$$
g(t, s):=\psi_{i-1}-Q_{m}\left(\psi_{i-1}\right)
$$

and interpolating property and the mean value theorem for two variables with $t_{0}=0$, and

Where

$$
t_{i}=\frac{1}{2^{n_{1}+1}}+\frac{v_{1}}{2^{n_{1}}}, s_{j}=\frac{1}{2^{n_{2}+1}}+\frac{v_{2}}{2^{n_{2}}},
$$

$$
\begin{aligned}
& \qquad \begin{array}{l}
i=2^{n_{1}}+v_{1}, \\
j=2^{n_{2}}+v_{2}, n_{1}, n_{2} \geq 1, i, j \leq m-1, \\
\text { we have } \\
\left\|\psi_{i-1}-Q_{m}\left(\psi_{i-1}\right)\right\|_{\infty} \\
=\| g\left(t_{i}, s_{j}\right)+\frac{\partial g}{\partial t}(\xi, \gamma)\left(\xi-t_{i}\right) \\
\quad+\frac{\partial g}{\partial t}(\xi, \gamma)\left(\gamma-s_{j}\right) \|_{\infty} \\
=\left\|\left(I-Q_{m}\right) \frac{\partial \psi_{i-1}}{\partial t}(\xi, \gamma)\left(I-Q_{m}\right) \frac{\partial \psi_{i-1}}{\partial s}(\xi, \gamma)\right\|_{\infty} \\
\max \left\{\left\|\xi-t_{i}\right\|_{\infty},\left\|\gamma-s_{j}\right\|_{\infty}\right\} \\
\leq \frac{2}{2^{i}}\left\|\left(I-Q_{m}\right)\right\|_{\infty}\left\|\frac{\partial \psi_{i-1}}{\partial t}(\xi, \gamma)+\frac{\partial \psi_{i-1}}{\partial s}(\xi, \gamma)\right\|_{\infty} \\
\leq \frac{4 L_{i-1}}{2^{i}},
\end{array}
\end{aligned}
$$

thus we have

$$
\left\|T\left(u_{i-1}\right)-u_{i}\right\|_{\infty} \leq(1+|\alpha|+|\beta|) \frac{4 L_{i-1}}{2^{i}},
$$

If $(1+|\alpha|+|\beta|) \frac{4 L_{k-1}}{2^{k}}<\varepsilon_{k}$, for $k=1,2, \ldots, i$, that $\varepsilon_{1}, \varepsilon_{2}, \ldots, \varepsilon_{i}>0$ for $i \geq 1$, we have $\left\|T\left(u_{i-1}\right)-u_{i}\right\|_{\infty}<\varepsilon_{i}(23)$.

Applying the triangle inequality and we achieve. 4 $\left\|u-u_{i}\right\|_{\infty} \leq$

$\left|u-T^{i}\left(u_{0}\right)\right|_{\infty}+\sum_{j=1}^{i} q^{i-j}\left\|T\left(u_{j-1}\right)-u_{j}\right\|_{\infty}$.

From (4.1) and (4.6) we conclude

$$
\begin{gathered}
\left\|u-u_{i}\right\|_{\infty} \leq\left\|T\left(u_{0}\right)-u_{0}\right\|_{\infty} \sum_{j=i}^{\infty} q^{j}+\sum_{j=1}^{i} q^{i-j} \varepsilon_{j} . \\
\text { IV. Numerical examples }
\end{gathered}
$$

In this section by using the method presented in (20) is solved some examples from different references. 
The main characteristic of this technique is that does not lead to a nonlinear algebraic equations system. The following algorithm, based on the method presented in Section 3, has been used to solve Examples.

Algorithm 5.1

1. Produce matrices $\boldsymbol{H}(t), \widehat{\boldsymbol{\Phi}}_{m \times m}$, and $\boldsymbol{P}$.

2. For $i=1$ to $k$ do,

3. Product Matrix $K_{t}, \widehat{K}_{t}$, for $t=1,2,3$ from (14) to (17) and (18).

4. Compute $Q_{m}\left(\psi^{t}\right)(x, t)$ for $t=1,2,3$ from (11) to (13).

5. Compute $u_{i}(x, y)$ from (20) for the assumed point.

6. Go to step 2.

Example 5.1. [15] consider the special case of Cauchy problem equation on $X=[0,1] \times[0,1]$

$$
\begin{aligned}
& u(x, t) \\
& =\frac{1}{4} \int_{0}^{t} \int_{0}^{x}\left\{\sin (u(y, z)) \cos \left(\frac{y-z}{2}\right) \sin \left(\frac{y+z}{2}\right)\right. \\
& \left.+\cos (u(y, z)) \sin \left(\frac{y-z}{2}\right) \cos \left(\frac{y+z}{2}\right)\right\} d y d z \\
& -\frac{1}{4} \int_{0}^{x}\{\sin (u(y, t))+\cos (u(y, t))-\sin (u(y, 0)) \\
& +\frac{1}{4} \int_{0}^{t}\{\cos (u(x, z))+\cos (u(y, 0))\} d y \\
& \quad+\sin (u(0, z))\} d z+\sin ^{2}\left(\frac{x}{2}\right)-\sin ^{2}\left(\frac{t}{2}\right) .
\end{aligned}
$$

The exact solution is $u(x, t)=\sin \left(\frac{x+t}{2}\right) \sin \left(\frac{x-t}{2}\right)$. The comparison between the approximate solutions obtained by Haar wavelet method and Legendre polynomials method( [13]) is given in Table1. There is a good agreement between these methods. In Fig. 1, we have shown a error equations. In this example the run time for $m=64$ is about 46.828 seconds.

Table 1. Numerical results for Example 5.1
\begin{tabular}{|c|c|c|c|}
\hline$\left(x_{i}, t_{i}\right)$ & $\begin{array}{c}\text { Legendre } \\
\text { polynomials } \\
\text { method } \\
([13])\end{array}$ & $\begin{array}{c}\text { Presented } \\
\text { method } \\
\text { With } \\
m=2^{5}\end{array}$ & $\begin{array}{c}\text { Presented } \\
\text { method } \\
\text { With } \\
m=2^{6}\end{array}$ \\
\hline$(0.0 .2)$ & $1.5 \times 10^{-6}$ & 0 & 0 \\
\hline$(0.2,0.4)$ & $6.4 \times 10^{-6}$ & $2.19 \times 10^{-6}$ & $5.89 \times 10^{-7}$ \\
\hline$(0.3,0.6)$ & $5.6 \times 10^{-6}$ & $2.93 \times 10^{-6}$ & $7.36 \times 10^{-7}$ \\
\hline$(0.4,0.8)$ & $3.5 \times 10^{-5}$ & $3.53 \times 10^{-6}$ & $9.29 \times 10^{-7}$ \\
\hline$(0.8,1)$ & $3.3 \times 10^{-6}$ & $2.80 \times 10^{-6}$ & $7.26 \times 10^{-7}$ \\
\hline
\end{tabular}

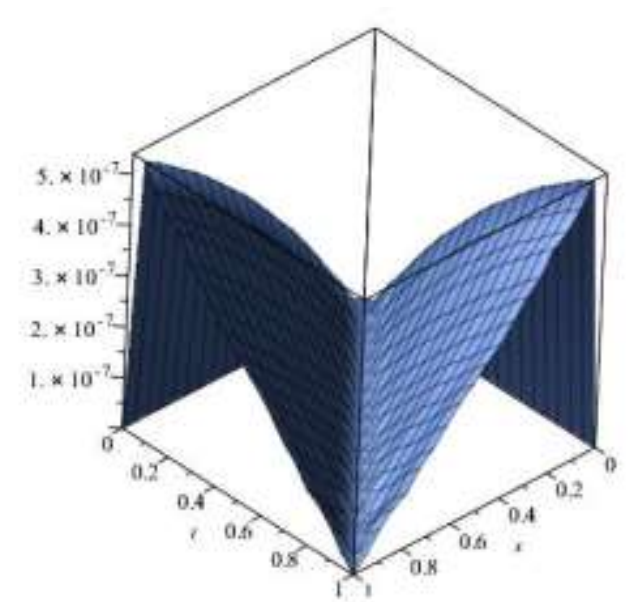

Figure 1: Error function for Example 5.1

\section{References}

[1] K. E. Atkinson, The Numerical Solution of Integral Equations of the Second Kind, Cambridge University Press, 1997.

[2] Brunner H, Kauthen J-P, The numerical solution of twodimensional Volterra integral equations by collocation and iterated collocation. IMA J Numer Anal 1989;9:47-59.

[3] R.T. Lynch, J.J. Reis, Haar transform image conding, Proceedings of the National Telecommunications Conference, Dallas, TX, (1976), 441-443.

[4] Kauthen JP, Continuous time collocation method for Volterra Fredholm integral equations, Numer Math 1989;56:409-24. [5] M. Razzaghi, J. Nazarzadeh, Walsh functions, Wiley Encyclopedia of Electrical and Electronics Engineering 23 (1999) 429-440.

[6] Brunner H. On the numerical solution of nonlinear Volterra Fredholm integral equations by collocation methods, SIAM J Numer Anal 1990;27(4):987-1000

[7] S. Nemati, P.M. Lima, Y. Ordokhani, Numerical solution of a class of two-dimensional nonlinear Volterra integral equations using Legendre polynomials, J. Comput. Appl. Math. Volume 242, April 2013, Pages 53-69.

[8] J.J. Reis, R.T. Lynch, J. Butman, Adaptive Haar transform video bandwidth reduction system for RPVs, Proceedings of Annual Meeting of Society of Photo-Optic Institute of Engineering (SPIE), San Dieago, CA, (1976) 24-35.

[9] S. Mckee, T. Tang, T. Diogo, An Euler-type method for twodimensional Volterra integral equations of the first kind, IMA J. Numer. Anal. 20 (2000) 423-440.

[10] P. Wojtaszczyk, A Mathematical Introduction to Wavelets, Cambridge University Press, 1997. 